\title{
Factors Affecting Membrane Distillation Process for Seawater Desalination
}

\author{
Ngo Thi Tra My, Vo Thi Yen Nhi, Bui Xuan Thanh* \\ Faculty of Environment and Natural Resources, Ho Chi Minh City University of \\ Technology, Vietnam
}

Submitted: 1/5/2018. Revised edition: 20/5/2018. Accepted: 25/05/2018. Published online: 4/6/2018

\begin{abstract}
Membrane distillation (MD), a process based on the thermal principle, is a combination of distillation and membrane separation in the same unit. There are many factors that can affect the MD performance, but the membrane characteristics are the most important in this process. The changes in the membrane properties affect the process efficiency, the permeate flux as well as the membrane lifetime. Some of the membrane properties mentioned in this paper include liquid entry pressure (LEP), contact angle, pore size, porosity, thickness, thermal conductivity, support layer, tortuosity, etc. This review paper aims to evaluate the membrane properties in order to reduce membrane wetting and to improve desalination efficiency. From this review, it can be seen that the LEP and contact angle are the important factors which directly affect the hydrophobicity of the membrane. When LEP and the contact angle increase, the hydrophobicity of the membrane increases. Thus, the membrane is durable and the MD system works efficiently. The remaining factors indirectly affect the operation of the MD system through LEP and contact angle (hydrophobicity).
\end{abstract}

Keywords: Membrane distillation, membrane properties, membrane parameters

\subsection{INTRODUCTION}

Nowadays, the increasing demand for fresh water and water shortage are the challenging issues that all people in the world concern about. The population grows, followed by the development of industries and the climate change makes fresh water progressively reduced. It is reported that more than 4 billion people around the world faced water shortage for at least a few months in 2016 [1]. Similar studies indicated that the area of surface water was in scarcity and more than $20 \%$ of the world's population will be deprived of water [2]. Although more than twothirds of the earth's surface is covered by water, $99.3 \%$ of the water is sea water or unusable [3]. Therefore, saltwater desalination is a promising solution to provide clean water for humanity.

Nowadays, there are several desalination technologies for seawater treatment plants in the world, such as RO, ED, MF-UF-NF, conventional distillation techniques, etc. However, these methods are still limited. For the RO process, for example, it requires high pre-treatment of seawater and the removal of organic matters is difficult [4]. ED operates less efficiently than other technologies when the salinity increased [5], during long-term operation using MF membrane, the 
removal efficiency decreases due to fouling and concentration polarization [6], which will increase the treatment cost. Meanwhile, MD overcomes the disadvantages of the above technologies. For example, it is possible to remove ions and colloidal matters from seawater, the quality of distilled water is very high and desalination efficiency is almost 99-100\% [5]. In addition, the feed water did not require conventional pretreatment and can simultaneously treat water sources with extremely high TDS concentration [5], so it is technically feasible to treat seawater. In addition, MD combines the use of waste heat and new energy to reduce the operation costs [7]. Therefore, MD could be the ideal technology for seawater desalination in the coming decades.

In the past, MD was not effectively commercialized for desalination purposes [8]. There were two main factors that hinder its development: membrane materials did not meet the required characteristics of the MD process and membrane costs were not reasonable $[9,10]$. Therefore, in the application of $\mathrm{MD}$, the membrane properties were the most important factor. However, these past reviews generally only included the overview about MD process [11, 12], scaling and fouling in MD and how to solve it [13, 14], and the recent development of MD technology and its applications $[15,16]$ and the theory of MD [17]. Some reviews evaluated some effects of membrane characteristics, but it is really general. It did not explain the properties of the membrane affecting the membrane operation as well as the MD process, and it had not given some appropriate values for the MD process $[17,18]$. Therefore, the determination of membrane design parameters is essential to apply MD technology in full-scale sytems.

The objective of this review is to focus on recent studies on membrane properties to provide the most suitable membrane parameters for the membrane design in MD system, as well as more specifically explaining the suitable range which the membrane parameters should be complied to improve seawater desalination of MD processes.

\subsection{FACTORS AFFECTING MEMBRANE DISTILLATION}

Membrane distillation (MD) was mentioned for desalination in the late 1960s [19] as a separation process combining membrane separation and evaporation. As a barrier, membrane separated vapor and water from the bulk solution, and then the vapor diffused through the membrane pores and condensed at the permeability of the membrane [11]. Based on the operating mode, the MD was divided into four main configurations: Direct Contact Membrane Distillation (DCMD), Vacuum Membrane Distillation (VMD), Sweeping Gas Membrane Distillation (SGMD) and Air Gap Membrane Distillation (AGMD) [11]. The dynamics of MD was the difference in vapor pressure on the membrane surface, so the MD process should meet the following criteria:

- The membrane must have a suitable thickness since the thickness was inversely proportional to the mass and heat transfer rate through the membrane $[3,8,20]$.

- The distribution of narrow membrane pores was recommended. When the pores were narrow, the water cannot penetrate the membrane pores and create wetting. The size of membrane pores oscillated in the range between few nanometers and few micrometers [3].

- Liquid entry pressure (LEP) is the 
minimum pressure at which water passed through the membrane pores. High LEP is recommended for using in an effective and longlasting MD process. If LEP is low, the membrane will be wet, which will affect the quality of distilled water $[11,17]$.

- The higher porosity was, the more flux reached. However, the high porosity will reduce the membrane efficiency $[3,17,21,22]$.

- Tortuosity should be as low as possible [3, 17].

- Surface energy should be as low as possible. This is equivalent to high hydrophobicity [17].

- The thermal conductivity of the membrane material should be as low as possible [3, 17].

- Membranes must have good thermal stability; membrane material should be resistant to chemical corrosion and have a long lifespan to improve the performance of the MD process [17].

Specifically, factors affecting the MD membrane are as follows.

\subsection{Liquid Entry Pressure (LEP)}

In membrane distillation process, the water cannot pass through the hydrophobic membrane. However, at a certain pressure, the water goes into the membrane pore; this pressure is called as liquid entry pressure (LEP) [13]. LEP was an important property of the membrane because it showed the hydrophobicity of the MD membrane, which allowed vapor to pass through without liquid. When the liquid penetrated the membrane, wetting will affect the distilled water quality. Therefore, in order to avoid wetting, it was necessary to control the inlet pressure. LEP calculation could be conducted by using the Laplace-Young equation [23]:
$L E P=\Delta P=P_{f}-P_{d}=\frac{-2 B \gamma_{1} \cos \theta}{r_{\max }}$

where $P_{f}$ and $P_{d}$ are hydraulic pressures on the feed and permeate stream, respectively; $\mathrm{B}$ is a geometric factor of membrane pore; $\gamma_{1}$ is the liquid surface tension; $\theta$ is the contact angle; $r_{\max }$ is the largest pore radius.

LEP was affected by the surface tension of the liquid, geometry, surface energy and pore size of the membrane. When membrane pore size rose, LEP decreased, the liquid was easier to penetrate into the membrane, and thus it was encouraged to use small pore size membranes. The hydrophobicity of the membrane increased as the LEP increased. Therefore, to increase LEP, one of some conditions should be improved:

- The membrane material should be hydrophobic;

- The increase of the membrane contact angle;

- The membrane pore size should be small.

The minimum operating LEP at which membrane was not wetted was 2.5 bar [18]. In addition, the LEP directly related to the hot - cool stream temperature, input composition and concentration and presence of dissolved organic matter [11]. For example, according to Gostoli and Sarti [24], for ethanol recovery by the MD process, most organic solvents can be permeable through hydrophobic membranes, including ethanol. When using a hydrophobic PTFE membrane and the LEP of at least 2.7 bar (> 2.5 bar) to separate the ethanol-water mixture, pure ethanol is still bonded by the membrane, effecting on the hydrophobic of the membrane. However, it can be clearly seen that when ethanol concentration is high, LEP of the mixture is low and it goes to 0 bar when the concentration is up to $75 \%$ of the ethanol mass. Therefore, to separate the ethanol-water mixture by 
$\mathrm{MD}$, in addition to considering the LEP, feed concentration should be noticed as well. The combination of low concentration of ethanol and high liquid entry pressure is a solution to prevent the permeability of organic solvents through the membrane. Also, the presence of surfactants in the solution would cause the LEP to decrease rapidly, and when its concentration increased, the membrane became wet $[23,25]$.

\subsection{Contact Angle}

Contact angle $(\theta)$ is the angle where a liquid-vapor interface meets a solid surface and this space includes liquid, vapor and solid [26]. Depending on the contact angle of the membrane, the hydrophobicity and wetting of the membrane surface can be calculated $[27,28]$. The contact angles which were small $\left(<90^{\circ}\right)$ had high permeability, while bigger contact angles $\left(>90^{\circ}\right)$ had low permeability [26]. According to some studies, the pore size, surface texture, and roughness of membrane could influence the contact angle [29]. To prevent penetration of the liquid into the membrane, this contact angle was greater than $90^{\circ}[23,27]$, ranging from $90^{\circ}$ to $150^{\circ}$, or it can reach up to $180^{\circ}$ [27]. The membrane contact angle could be calculated by using the following formula:

$\cos \theta=\frac{\gamma_{1}-\gamma_{s}}{\gamma_{\mathrm{lv}}}$

where $\gamma_{1}, \gamma_{\mathrm{s}}, \gamma_{l_{\mathrm{v}}}$ are liquid, solid, vaporliquid interfacial tension, respectively.

Some works on the efficiency of membrane distillation system related to contact angle were investigated, which is presented in Table 1. The contact angle (hydrophobicity) of the membrane was maintained by modifying the membrane surface to stabilize the process efficiency at a high level.

\subsection{Membrane Pore Size}

The membrane pore sizes effected on permeate flux and wetting, so it was an influencing factor of the MD membrane [32]. Selection of the membrane pore size should be carefully considered. When the pores were too large, the water easily passed through the membrane, which creates membrane wetting. Otherwise, when the membrane pores were too small, the vapor crossed the membrane will be less, so the permeate flux will reduce [33]. To be sure the operating temperature and pressure change could not cause wetting of the membrane, it was recommended that the membrane pore size was between 0.1 and $0.6 \mu \mathrm{m}$ $[23,11]$.

In addition, according to Equation (1), when the membrane pore radius was large, the membrane may be wetted, so, the application of the small pore size membrane should be chosen. This was also found in the study of Naim and Abdullah [34]. The other research showed that in Direct Contact Membrane Distillation system, to avoid wetting, the pore size of the membrane that is recommended is less than $0.5 \mu \mathrm{m}$ [11]. For the same porosity, the thermal polarization coefficient of the pore size of $0.22 \mu \mathrm{m}$ was higher than $0.45 \mu \mathrm{m}$. This was due to the limited pore size of the membrane, resulting in reducing heat transfer by vaporization and decreasing permeate flux [33]. In another study, for the membrane materials made from Polytetrafluoroethylene - PTFE, when the pore size rose from 0.22 to $0.45 \mu \mathrm{m}$, the permeate flux increased by $8 \%$ [33]. 
Table 1 Some studies on removal efficiency of MD system related to contact angle

\begin{tabular}{|c|c|c|c|}
\hline Operating conditions & $\begin{array}{c}\text { Contact } \\
\text { angle }(\theta)\end{array}$ & Results & Ref \\
\hline $\begin{array}{l}\text { PTFE membrane; } \\
\mathrm{T}_{\mathrm{f}}=80^{\circ} \mathrm{C} ; \\
\mathrm{P}_{\mathrm{p}}=30 \mathrm{kPa}, \\
\text { Feed concentration }= \\
3.5 \%(\mathrm{NaCl})\end{array}$ & $\begin{array}{c}136.1- \\
157.3\end{array}$ & $\begin{array}{l}\text { - Membrane contact angle was adjusted } \\
\text { by changing the sintering temperature } \\
\text { of the PTFE materials. } \\
\text { - Salt removal efficiency }>98.5 \text {. }\end{array}$ & [22] \\
\hline $\begin{array}{l}\text { PVDF membrane; } \\
\mathrm{T}_{\mathrm{f}}=29.1-66.3^{\circ} \mathrm{C} ; \\
\mathrm{T}_{\mathrm{p}}=10.3-50.4^{\circ} \mathrm{C} ; \\
\text { Feed concentration }= \\
3.775 \mathrm{mM}\left(\mathrm{CaCl}_{2}\right)\end{array}$ & 111 & $\begin{array}{l}\text { Mass transfer coefficients of PTFE and } \\
\text { PVDF membranes were the same } \\
\text { although the membrane thickness } \\
\text { varied. The reason was due to the } \\
\text { difference in membrane pore size } \\
\text { distribution. } \\
\text { - Permeate flux reached } 9.3 \mathrm{~kg} / \mathrm{m}^{2} . \mathrm{h} \text {. }\end{array}$ & {$[30]$} \\
\hline $\begin{array}{l}\text { PTFE membrane; } \\
\mathrm{T}_{\mathrm{f}}=29.3-69.8^{\circ} \mathrm{C} ; \\
\mathrm{T}_{\mathrm{p}}=12.6-41.3^{\circ} \mathrm{C}, \\
\text { Feed concentration }= \\
3.775 \mathrm{mM}\left(\mathrm{CaCl}_{2}\right)\end{array}$ & 123 & $\begin{array}{l}\text { The mass transfer coefficients of PTFE } \\
\text { and PVDF membranes were the same } \\
\text { although the membrane thickness } \\
\text { varied. The reason was explained by } \\
\text { the difference in membrane size } \\
\text { distribution. } \\
\text { - Permeate flux reached } 7.8 \mathrm{~kg} / \mathrm{m}^{2} . \mathrm{h} \text {. }\end{array}$ & {$[30]$} \\
\hline $\begin{array}{l}\text { PP membrane; } \\
\mathrm{T}_{\mathrm{f}}=60.3^{\circ} \mathrm{C} \\
\mathrm{T}_{\mathrm{p}}=18.9^{\circ} \mathrm{C} \\
\mathrm{TDS}=4749 \mathrm{mg} / \mathrm{L} .\end{array}$ & $128-132$ & $\begin{array}{l}\text { - The cooling tower blowdown water is } \\
\text { effectively recovered by this MD } \\
\text { technology. } \\
\text { - Salt removal efficiency } ~ 99.95 \% \text {. }\end{array}$ & [31] \\
\hline
\end{tabular}

The larger the pore size was, the higher the permeate flux was. It could be clearly shown that when the feed temperature increased, the vapor pressure across the membrane would increase [35]. However, it should be noted that the non-linearity occurs between pore size and permeate flux. For MD process, the pore size of the hydrophobic membrane was not larger than $1 \mu \mathrm{m}$ typically used. Otherwise, the surface energy and the hydrophobicity of the membrane decreased, resulting in membrane wetting and thus reducing the removal efficiency of the process [33].

\subsection{Porosity}

In addition to the LEP, contact angle and pore size, the porosity was also an important element in the MD process. The porosity relates to the rate at which transferred mass through the membrane in the membrane distillation process. Porosity was the space which the vapor could pass through. Generally, mass transfer process occurred in MD system by convective or vapor diffusion, which could be described by the Knudsen diffusion model and molecular diffusion [17]. This could be described by the following equation [23]:

$$
\begin{aligned}
& \mathrm{D}_{\mathrm{ie}}^{\mathrm{k}}=\frac{2 \varepsilon \mathrm{r}}{3 \tau} \sqrt{\frac{8 \mathrm{RT}}{\pi \mathrm{M}_{\mathrm{i}}}} \\
& \mathrm{D}_{\mathrm{ije}}^{0}=\frac{\varepsilon}{\tau} \mathrm{D}_{\mathrm{ij}}
\end{aligned}
$$

where $D_{i e}^{k}$ is the effective Knudsen diffusivity; $D_{i j e}^{0}$ is the effective molecular diffusivity; $D_{i j}$ is the molecular diffusivity; $\varepsilon$ is the membrane porosity; $\tau$ is the membrane tortuosity; $\mathrm{r}$ is the mean pore radius; $\mathrm{M}$ is the molecular weight; $\mathrm{i}$ and $\mathrm{j}$ are vapor and air, respectively. 
Based on the formula, the greater the porosity was, the faster the diffusion of vapor molecules crossed the membrane, so, the lower the thermal conductivity crossed the membrane, resulting in flux increase. In hence, it could indicate that the results were consistent with the study by Khalifa et al. [33], permeate flux of MD system increased with the porosity while thermal polarization slightly decreased with increasing the porosity. Depending on the membrane materials, tubular, flat sheet or hollow fiber membrane and the method that created the completed membrane, the porosity of membrane was between $60 \%$ and $90 \%$, [35]. Generally, 80\% porosity was recommended for all MD configurations [18].

\subsection{Membrane Thickness}

The thickness of membrane was one of the important characteristics that could affect permeate flux during operation [32]. Thickness was studied in the range of $20-400 \mu \mathrm{m}$ [36], however, the range of $10-60 \mu \mathrm{m}$ that were also demonstrated by many researchers had good desalination efficiency [18]. Another work showed that effective membrane thickness for MD process ranged from 30 to $60 \mu \mathrm{m}$ [11]. As membrane thickness increased, the diffusion distance of the vapor molecules increased, thereby impeding mass transfer, leading to reducing flux [11]. Conversely, the decline of membrane thickness improved the mass transfer, hence, permeate flux increased [20]. Therefore, the optimal thickness for membrane depended on the type of membrane and input salinity [32]. For the multilayer membranes, it was recommended that the thickness of the hydrophobic layer is as thin as possible, with good mass transfer and to reduce heat loss through the membrane, the overall thickness (hydrophobic and hydrophilic) should be as thick as possible [17]. Table 2 shows some desalination studies by MD processes that were related to the thickness of the membrane.

Table 2 Some studies on MD system with the difference of contact angle

\begin{tabular}{|c|c|c|c|}
\hline $\begin{array}{c}\text { Membrane } \\
\text { thickness }(\mu \mathrm{m})\end{array}$ & Operating conditions & $\begin{array}{c}\text { Flux } \\
\left(\mathrm{kg} / \mathrm{m}^{2} . \mathbf{h}\right)\end{array}$ & Ref \\
\hline$\delta=65 \mu \mathrm{m}$ & $\begin{array}{l}\text { PTFE membrane, } \mathrm{d}=0.20 \mu \mathrm{m}, \varepsilon=62 \% \\
\text { MD } \\
\mathrm{CaCl}_{2}=3.775 \mathrm{mM} \\
\mathrm{T}_{\mathrm{f}}=51.6^{\circ} \mathrm{C} \& \mathrm{~T}_{\mathrm{p}}=24.7^{\circ} \mathrm{C}\end{array}$ & $1.0-18.4$ & [30] \\
\hline$\delta=125 \mu \mathrm{m}$ & $\begin{array}{l}\text { PVDF membrane, } \mathrm{d}=0.22 \mu \mathrm{m}, \varepsilon=75 \% \\
\mathrm{MD} \\
\mathrm{CaCl}_{2}=3.775 \mathrm{mM} \\
\mathrm{T}_{\mathrm{f}}=52.2^{\circ} \mathrm{C} \& \mathrm{~T}_{\mathrm{p}}=25.6^{\circ} \mathrm{C}\end{array}$ & $1.7-23.3$ & [30] \\
\hline$\delta=100 \mu \mathrm{m}$ & $\begin{array}{l}\text { PP membrane, } d=0.1 \mu \mathrm{m}, \varepsilon=65-70 \% \\
\text { DCMD } \\
\text { TDS }=4749 \mathrm{mg} / \mathrm{L} \\
\mathrm{T}_{\mathrm{f}}=60.3^{\circ} \mathrm{C} \& \mathrm{~T}_{\mathrm{p}}=18.9^{\circ} \mathrm{C}\end{array}$ & 30 & [31] \\
\hline$\delta=160 \mu \mathrm{m}$ & $\begin{array}{l}\text { PTFE membrane, } d=0.22 \mu \mathrm{m}, \varepsilon=62 \% \\
\text { DCMD } \\
\mathrm{NaCl}=3.5 \% \\
\mathrm{~T}_{\mathrm{f}}=60^{\circ} \mathrm{C} \& \mathrm{~T}_{\mathrm{p}}=20^{\circ} \mathrm{C}\end{array}$ & 25.6 & [37] \\
\hline
\end{tabular}




\subsection{Thermal Conductivity}

MD was a non-isothermal process, so thermal conductivity was an important factor in the performance of the MD system. Some factors including the hot -cool stream temperature, crystallinity, and shape of the crystal polymer effected on this MD process [11]. It could be calculated by the formulation [23]:

$$
\begin{aligned}
\mathrm{h}_{\mathrm{m}} & =\varepsilon \mathrm{h}_{\mathrm{mg}}+(1-\varepsilon) \mathrm{h}_{\mathrm{ms}} \\
& =\mathrm{h}_{\mathrm{ms}}-\varepsilon\left(\mathrm{h}_{\mathrm{ms}}-\mathrm{h}_{\mathrm{mg}}\right) \\
Q_{m} & =h_{m} \times \Delta T_{m}
\end{aligned}
$$

where $\mathrm{Q}$ is heat conducted through the membrane material; $\Delta T_{m}$ is temperature difference on the membrane surface; $h_{m}$ is the thermal conductivity of the membrane; $\varepsilon$ is the membrane porosity; $\mathrm{h}_{\mathrm{mg}}$ is thermal conductivity of the gas through the membrane pores, and $\mathrm{h}_{\mathrm{ms}}$ is thermal conductivity of solid membrane material.

Because the heat transfer coefficient of the gas was smaller than that of the solid, the equation (5) could show that $\mathrm{h}_{\mathrm{m}}$ value could be minimized by increasing the porosity of the membrane. Hence, the porosity could reduce the amount of lost heat due to conductivity.

As mean pore size and tortuosity were considered constant factors, the lowest thermal conductivity of membrane resulted in the highest permeate flux [11, 18]. When the membrane material had a high thermal conductivity, the heat resistance was less, the heating stream through the membrane increased, which made both the vapor stream and thermal efficiency decreased. Lia et al. [38] investigated that heat conduction increased from 0.01 to $0.05 \mathrm{~W} / \mathrm{mK}$, vapor stream decreased from 45 to $33 \mathrm{~kg} / \mathrm{m}^{2} \mathrm{~h}$; simultaneously, thermal efficiency decreased from $83 \%$ to $47 \%$. Therefore, the active layer of the membrane should be made of a material which had a small thermal conductivity to avoid heat loss, for this MD process, ordinary hydrophobic polymers were typically $0.2 \mathrm{~W} / \mathrm{mK}$ [39].

\subsection{Support Layer}

In order to achieve high efficiency and improve permeate flux, attaching a support layer was used in many studies. This layer supported heat insulation, increased the strength of the membrane and protected the membrane from damage during operation [15]. This support layer might consist of several hydrophobic layers or hydrophobic layers combined with hydrophilic layers [17]. The hydrophobic property of membrane prevented water from bulk solution penetrating the membrane, allowing vapor stream to pass through the membrane. As mentioned above, the hydrophobic layer was as thin as possible [15] and the purpose of the hydrophilic layer was to increase the heat resistance of the membrane [17].

The most common supported materials used for MD membranes were polypropylene (PP), polysulfone (PS), and polyethylene terephthalate (PET) [35]. According to Zhu et al. [29], for the membrane with the same PTFE material and pore size of $0.2 \mu \mathrm{m}$, the desalination efficiency of the nonsupported layer membrane was higher than that of the supported layer one. This might be explained by the supported layer covered membrane pores and reduced porosities. Furthermore, supported material absorbed heat from the inlet, followed by the increase in the temperature polarization [35]. On the cool side of MD system, the support layers which made from hydrophilic material reduced the flux to $56 \%$ [35]. 
The use of one hydrophobic membrane layer that is thinner with the large pore size will lead to increase permeate flux. However, this membrane will not be durable and susceptible. Therefore, it is necessary to combine this thin hydrophobic membrane with the other hydrophilic support layer which thicker will increased membrane hardness and protected the membrane. On the other hand, the thick support layer increased the thermal polarization, thereby reducing the flux. So, studies on the thickness adjustment of each layer have been made and led to feasible results. As thin hydrophobic membranes with a thickness of fewer than $10 \mu \mathrm{m}$ combined with a hydrophilic layer that was thicker than $90 \mu \mathrm{m}$ and pore size was bigger than the hydrophobic membrane, it would reach higher efficiency and permeate flux [40].

\subsection{Tortuosity and Membrane Pore Size Distribution}

The MD process is also affected by tortuosity which determined the effective direction of vapor molecules crossing the membrane [41]. Tortuosity of the pore membrane depended on the shape of the pore and the production method. It was a function of porosity, expressed by the following formula [42]:

- For polymer membrane:

$$
\frac{\tau}{\varepsilon}=\frac{(2-\varepsilon)^{2}}{\varepsilon}
$$

- For polymer structures of random clusters or fractal theories:

$$
\tau=\frac{1}{\varepsilon}
$$

where $\tau$ is tortuosity of the membrane, $\varepsilon$ is the membrane porosity. Permeate flux was improved as the tortuosity was lower and the porosity was higher [15]. The tortuosity of the MD membrane varied from 1 to 2 [3]. According to Khayet [17], the tortuosity needed to be adjusted for theoretical models to calculate flux. However, the effect of tortuosity on the permeability of MD was almost not mentioned in the studies. Besides, pore size distributions of the membrane also significantly influenced permeate flux [30]. Tan et al. [8] indicated that although the membrane thickness varied, the mass transfer coefficients of PTFE and PVDF membrane were the same. The reason was explained by the difference in membrane size distribution. However, the effect of the pore size distribution on mass transfer was not completely clear.

\subsection{CONCLUSION}

Membrane distillation is the combination of the distillation and the membrane separation. This process occurs under the action of heat, and then generated vapor is separated by a hydrophobic membrane. Interestingly, MD technology could achieve a high removal efficiency of total dissolved solids from seawater. However, this technology still encounters some challenges in terms of operating cost and membrane properties. Membrane wetting is one of the biggest limitations in membrane distillation process which need to be improved for more real application in the coming decades.

\section{ACKNOWLEDGMENT}

This research is partly funded by Ho Chi Minh City University of Technology - VNU-HCM under grant number TSĐH-MTTN-2017-21. This study has been conducted under the framework of CARE-RESCIF initiative. The authors would like to thank collaborators (Ms. L.T. Huong, Ms. L.S. Kin, Ms. N.T.D. Ngoc \& Ms. Sagnimorte Aude) for their support. 


\section{REFERENCES}

[1] M. M. Mekonnen, A. Y. Hoekstra. 2016. Four Billion People Facing Severe Water Scarcity. Sci. Adv. 2: 1-6.

[2] J. Deshpande, K. Nithyanandam, R. Pitchumani. 2017. Analysis and Design of Direct Contact Membrane Distillation. $J$. Membr. Sci. 523: 301-316.

[3] M. R. Qtaishat, F. Banat. 2013. Desalination by Solar-powered Membrane Distillation Systems. Desalination. 308: 186-197.

[4] A. F. Ismail, K. C. Khulbe, T. Matsuura. 2017. Recent Progress in Reverse Osmosis (RO) Science and Technology. J. Applied Membrane Science \& Technology. 21: 1-10.

[5] J. Morillo, J. Usero, D. Rosado, H. E. Bakouri, A. Riaza, F. J. Bernaola. 2014. Comparative Study of Brine Management Technologies for Desalination Plants. Desalination. 336: 32-49.

[6] A. Laorko, S. Tongchitpakdee, W. Youravong. 2015. Economic Assessment for Cold Sterilization and Clarification of Pineapple Juice and Coconut Water Using Microfiltration. J. Applied Membrane Science \& Technology. 17: 35-46.

[7] A. M. Elzahaby, A. E. Kabeel, M. M. Bassuoni, A. R. A. Elbar. 2016. Direct Contact Membrane Water Distillation Assisted with Solar Energy. Energy Conversion and Management. 110: 397-406.

[8] L. M. Camacho, L. Dumée, J. Zhang, J. Li, M. Duke, J. Gomez, S. Gray. 2013. Advances in Membrane Distillation for Water Desalination and Purification Applications: A Review. Water. 5: 94-196.

[9] A. M. Alklaibi, N. Lior. 2005. Membrane-distillation
Desalination: Status and Potential. Desalination. 171: 111131.

[10] W. T. Hanbury, T. Hodgkiess. 1985. Membrane DistillationAn Assessment. Desalination. 56: 287-297.

[11] A. Alkhudhiri, N. Darwish, N. Hilal. 2012. Membrane Distillation: A Comprehensive Review. Desalination. 287: 2-18.

[12] A. Subramani and J. G. Jacangelo. 2015. Review: Emerging Desalination Technologies for Water Treatment: A Critical Review. Water Research. 75: 164-187.

[13] L. D. Tijing, Y. C. Woo, J. S. Choi, S. Lee, S. H. Kim, H. K. Shon. 2015. Fouling and Its Control in Membrane Distillation-A Review. $J$. Membr. Sci. 475: 215-244.

[14] D. M. Warsinger, J. Swaminathan, E. GuillenBurrieza, H. A. Arafat, J. H. Lienhard. 2015. Scaling and Fouling in Membrane Distillation for Desalination Applications: A Review. Desalination. 356: 294313.

[15] E. Drioli, A. Ali, F. Macedonio. 2015. Membrane Distillation: Recent Developments and Perspectives. Desalination. 356: 56-84.

[16] B. B. Ashoor, S. Mansour, A. Giwa, V. Dufour, S. W. Hasan. 2016. Principles and Applications of Direct Contact Membrane Distillation (DCMD): A Comprehensive Review. Desalination. 398: 222-246.

[17] M. Khayet. 2011. Membranes and Theoretical Modeling of Membrane Distillation: A Review. Adv. Colloid Interface Sci. 164: 56-88.

[18] L. Eykens, K. De Sitter, C. Dotremont, L. Pinoy, B. Van der 
Bruggen. 2017. Membrane Synthesis for Membrane Distillation: A Review. Sep. Purif. Technol. 182: 36-51.

[19] M. E. Findley. 1967. Vaporization through Porous Membranes. Ind. Eng. Chem. Proc. Des. Dev. 6: 226-230.

[20] L. Eykens, I. Hitsov, K. De Sitter, C. Dotremont, L. Pinoy, I. Nopens, B. Van der Bruggen. 2016. Influence of Membrane Thickness and Process Conditions on Direct Contact Membrane Distillation at Different Salinities. J. Membr. Sci. 498: 353-364.

[21] J. Li, Y. Guan, F. Cheng, Y. Liu. 2015. Treatment of High Salinity Brines by Direct Contact Membrane Distillation: Effect of Membrane Characteristics and Salinity. Chemosphere. 140: 143149.

[22] T. Zhou, Y. Yao, R. Xiang, Y. Wu. 2014. Formation and Characterization of Polytetrafluoroethylene

Nanofiber Membranes for Vacuum Membrane Distillation. J. Membr. Sci. 453: 402-408.

[23] K. W. Lawson, D. R. Lloyd. 1997. Membrane Distillation. $J$. Membr. Sci. 124: 1-25.

[24] C. Gostoli, G.C. Sarti. 1989. Separation of Liquid Mixtures by Membrane Distillation. $J$. Membr. Sci. 41: 211-224.

[25] J. Ge, Y. Peng, Z. Li, P. Chen, S. Wang. 2014. Membrane Fouling and Wetting in a DCMD Process for RO Brine Concentration. Desalination. 344: 97-107.

[26] Y. Yuan, T. R. Lee. 2013. Contact Angle and Wetting Properties. Surf. Sci. Tech. 51: 3-34.

[27] A. K. Fard, Y. Manawi. 2014. Seawater Desalination for Production of Highly Pure Water Using a Hydrophobic PTFE
Membrane and Direct Contact Membrane Distillation (DCMD). WASET. 8: 391-399.

[28] S. N. W. Ikhsan, N. Abdullah, N. Yusof, F. Aziz, N. Misdan, N. H. H. Hairom. 2017. Polyethersulfone/HFO Mixed Matrix Membrane for Enhanced Oily Wastewater Rejection. $J$. Applied Membrane Science \& Technology. 20: 11-17.

[29] H. Zhu, H. Wang, F. Wang, Y. Guo, H. Zhang, J. Chen. 2013. Preparation and Properties of PTFE Hollow Fiber Membranes for Desalination Through Vacuum Membrane Distillation. J. Membr. Sci. 446: 145-153.

[30] Y. Z. Tan, J. W. Chew, W. B. Krantz. 2016. Effect of Humicacid Fouling on Membrane Distillation. J. Membr. Sci. 504: 263-273.

[31] X. Yu, H. Yang, H. Lei, A. Shapiro. 2013. Experimental Evaluation on Concentrating Cooling Tower Blowdown Water by Direct Contact Membrane Distillation. Desalination. 323: 134-141.

[32] M. M. A. Shirazia, A. Kargari, M. Tabatabaei. 2014. Evaluation of Commercial PTFE Membranes in Desalination by Direct Contact Membrane Distillation. Chem. Eng. Process. 76: 16-25.

[33] A. Khalifa, H. Ahmada, M. Antar, T Laoui, M. Khayet. 2017. Experimental and Theoretical Investigations on Water Desalination Using Direct Contact Membrane Distillation. Desalination. 404: 22-34.

[34] R. Naim, S. Abdullah. 2015. Membrane Wetting in Membrane Contactor System: A Review. $J$. Applied Membrane Science \& Technology. 17: 9-15.

[35] S. Adnan, M. Hoang, H. Wang, Z. Xie. 2012. Commercial PTFE 
Membranes for Membrane Distillation Application: Effect of Microstructure and Support Material. Desalination. 284: $297-$ 308.

[36] A. Ali, C.A. Quist-Jensen, F. Macedonio, E. Drioli. 2016. On Designing of Membrane Thickness and Thermal Conductivity for Large-Scale Membrane Distillation Modules. JMSR. 2: 179-185.

[37] K. He, H. J. Hwang, M. W. Woo, I. S. Moon. 2017. Production of Drinking Water from Saline Water by Direct Contact Membrane Distillation (DCMD). Journal of Industrial and Engineering Chemistry. 17: 4148.

[38] Z. Lia, Y. Peng, Y. Dong, H. Fan, P. Chen, L. Qiu, Q. Jiang. 2014. Effects of Thermal Efficiency in DCMD and the Preparation of Membranes with Low Thermal
Conductivity. Appl. Surf. Sci. 317: 338-349.

[39] A. Luo, N. Lior. 2017. Study of Advancement to Higher Temperature Membrane Distillation. Desalination. 419: 88-100.

[40] M. Khayet, T. Matsuura, J.I. Mengual, M. Qtaishat. 2006. Design of Novel Direct Contact Membrane Distillation Membranes. Desalination. 192: 105-111.

[41] P. Wang, T. S. Chung. 2015. Recent Advances in Membrane Distillation Processes: Membrane Development, Configuration Design and Application Exploring. J. Membr. Sci. 474: 39-56.

[42] S. B. Iversen, V. K. Bhatia, K. Dam-Johansen, G. Jonsson. 1997. Characterization of Microporous Membranes for Use in Membrane Contactors. J. Membr. Sci. 130: 205-217. 